\title{
Research Letter \\ Effect of Ammonium Nitrate on Nanoparticle Size Reduction
}

\author{
Kalyana C. Pingali, Shuguang Deng, and David A. Rockstraw \\ Department of Chemical Engineering, New Mexico State University, P.O. Box 30001, MSC 3805, Las Cruces, NM 88003, USA \\ Correspondence should be addressed to Shuguang Deng, sdeng@nmsu.edu
}

Received 13 January 2008; Accepted 3 March 2008

Recommended by Ram B. Gupta

\begin{abstract}
Ammonium nitrate was added to the spraying solution as a foaming agent to reduce the particle size of nanoparticles synthesized in the spray-pyrolysis process. Ammonium nitrate was effective in breaking the aerosol droplet size and generating nanoparticles that were of approximately one order-of-magnitude (from 200 to $20 \mathrm{~nm}$ ) smaller diameter than those created in the absence of ammonium nitrate in the feed solution. This technique makes it possible to control the particle diameter of metallic nanoparticles below $20 \mathrm{~nm}$.
\end{abstract}

Copyright ( $) 2008$ Kalyana C. Pingali et al. This is an open access article distributed under the Creative Commons Attribution License, which permits unrestricted use, distribution, and reproduction in any medium, provided the original work is properly cited.

\section{INTRODUCTION}

Size control of nanoparticle diameter in the range of 10 $20 \mathrm{~nm}$ during the synthesis remains a technological challenge of current relevance. Spray pyrolysis was used to synthesize silver nanoparticles from aqueous silver nitrate solution [1]. To get the desired particle size, a concentration in the range of $10^{-7} \mathrm{M}$ of the feed solution was necessary. This will be problematic for the synthesis of commercial quantities of nanoparticles; the production rate of nanoparticles will be extremely low. It was observed that it becomes difficult to further reduce particle size by reducing concentration when the subnanometer range is approached. There is a need for a high-rate process that produces a particle size below $5 \mathrm{~nm}$ [2]. In this communication, the production of small nanoparticles at moderate feedstock precursor concentration is presented.

Various particle reduction techniques are described in the literature [3-9]. Several mechanisms and methods have been used to study the effect of ammonia on particle size. Arriagada and Osseo-Asare [3] observed that the presence of ammonia decreases the size of a microemulsion and final particle size. Ammonia was applied to synthesize nanocrystalline aluminum nitride powders with particle size of $8 \mathrm{~nm}$ [4]. Borgna et al. [5] observed a narrow particle size distribution with the introduction of ammonia gas in the feed stream. Ammonia gas was also used to synthesize fine metallic tin particles [6], where particle size was found to decrease as the ammonia gas flow rate increased. Thomas [7] employed ammonia catalyzed hydrolysis and observed that particle size was significantly affected. The study done by Park et al. [8] showed that the concentration of ammonia was one of the parameters affecting the particle size of silica nanoparticles.

The use of ammonia in spray pyrolysis has seen little attention in the literature. In this study, ammonia is generated in the aqueous phase of the droplet to reduce the aerosol size, thereby leading to the production of smaller particle size using a moderate to high precursor concentration in the feed solution.

\section{EXPERIMENTS}

Nanoparticles were generated by spray pyrolysis of aqueous feed solution which was gravity fed from the burette to an atomizer. The atomized spray was discharged into the reaction chamber that was maintained at a controlled temperature. Detail descriptions of the experimental apparatus and operation procedures can be found in our previous work [1]. Experiments were run with and without the addition of ammonium nitrate $\left(2.5 \times 10^{-4} \mathrm{M}\right)$ to the precursor feed solutions. Samples of metallic nanoparticles were collected on separate quartz plates at the bottom of the reactor kept perpendicular to the process flow path. Particle sizes of a sample were manually counted from the images obtained from TEM with a JEOL 200CX or SEM using a Hitachi 


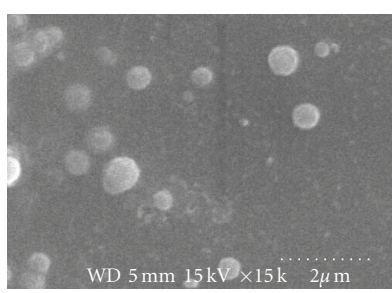

(a)

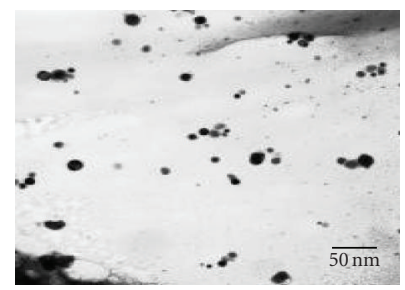

(b)
FIGURE 1: Size comparison of silver nanoparticles produced in the absence (a) and presence (b) of ammonium nitrate. Image (a) presents an SEM image of silver nanoparticle $(301 \mathrm{~nm})$ without ammonium nitrate; and Image (b) is a TEM image of nanoparticles $(17 \mathrm{~nm})$ produced with ammonium nitrate present. Both the experiments were run at $10^{-1} \mathrm{M}$ (precursor concentration), $700^{\circ} \mathrm{C}$ (operating temperature), and $8 \mathrm{~W}$ (atomizer power).

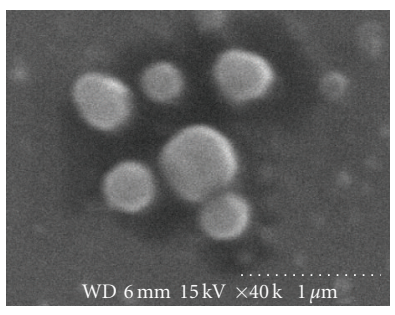

(a)

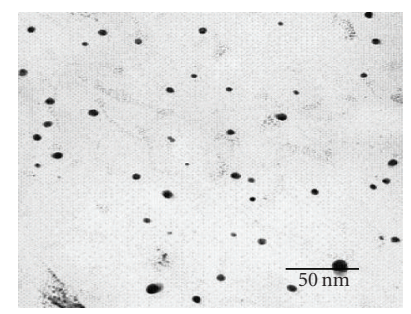

(b)
FIGURE 2: Size comparison of ruthenium nanoparticles produced in the absence (a) and presence (b) of ammonium nitrate. Image (a) is a SEM of ruthenium nanoparticles $(310 \mathrm{~nm})$ produced without ammonium nitrate; while Image (b) is a TEM of ruthenium nanoparticles $(10 \mathrm{~nm})$ produced with ammonium nitrate present. Both the experiments were run at $10^{-4} \mathrm{M}$ (precursor concentration), $700^{\circ} \mathrm{C}$ (operating temperature) and $5 \mathrm{~W}$ (atomizer power).

S-3200 N. Samples to be analyzed by TEM were collected on 200-mesh nickel grids with formvar coating.

\section{RESULTS AND DISCUSSION}

\subsection{Silver}

Nanoparticle samples were created both with and without ammonium nitrate in the feedstock solution for three sets of experimental conditions. Table 1 compares the size of the silver nanoparticles created both with and without ammonium nitrate in the process feed solution. A reduction in average particle size was observed when ammonium nitrate was present. Figure 1 shows the SEM and TEM images of silver nanoparticles without ammonium nitrate in the feed solution. When ammonium nitrate was added to the same solution feedstock, average particle size was reduced from 302 to $16 \mathrm{~nm}$. Such particle reduction in the presence of ammonia was described in previous studies [3-6]. In this work, it is hypothesized that ammonia gas generation leads to a physical destruction of the aerosol droplet as well as potentially affecting the surface tension of water. This can be viewed as a rapid phase transition created by chemical

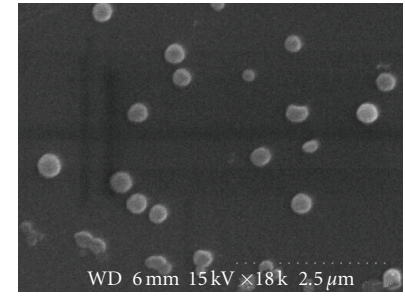

(a)

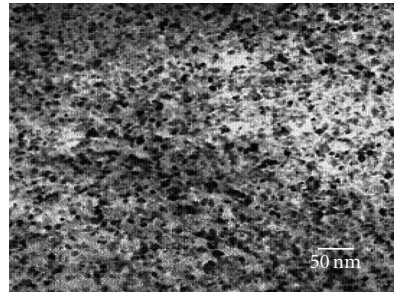

(b)
FIGURE 3: Size comparison of nickel nanoparticles produced in the absence (a) and presence (b) of ammonium nitrate. Image (a) is a SEM image of nickel nanoparticles $(246 \mathrm{~nm})$ produced without ammonium nitrate, while image (b) is a TEM image of particle size distribution of nickel nanoparticles $(9 \mathrm{~nm})$ produced with ammonium nitrate. Both experiments were run at $10^{-4} \mathrm{M}$ (precursor concentration), $700^{\circ} \mathrm{C}$ (operating temperature), and $5 \mathrm{~W}$ (atomizer power).

reaction (decomposition of ammonium nitrate), causing a violent mass transfer effect in the existing liquid phase. Ammonia gas formed in the pyrolysis process significantly reduces the size of aerosol droplets, resulting in a smaller nanoparticle size deposits.

\subsection{Ruthenium and Nickel}

Experiments were performed using other metal chloride systems, such as ruthenium and nickel, to synthesize metal nanoparticles of these metals. Ammonium nitrate was again used in these feed solutions. Table 2 compares the results of ruthenium nanoparticles synthesized from ruthenium chloride with ammonium nitrate present in the feed solution. SEM and TEM images as shown in Figure 2 were obtained for ruthenium nanoparticles and used to determine the average diameter of the particles. The effect of ammonium nitrate was expected to reduce the particle size, therefore a high feed solution concentration was employed, whereas atomizer power and reactor temperature were kept at lower limits in the operating range. This afforded the flexibility to operate the experiment at optimum reactor conditions. Nanoparticles of larger average size were synthesized from a higher feed solution concentration; yet an average particle size of less than $50 \mathrm{~nm}$ was obtained with a relatively monodisperse size distribution. A similar distribution was observed for particles of less than $20 \mathrm{~nm}$ diameter. The average particle size may also depend on the density of solution, which varies with the nature of the solution, though this effect would be expected to be minor.

Table 3 shows the results of nickel nanoparticles synthesized from nickel chloride with ammonium nitrate present in the feed solution. Similar to silver and nickel nanoparticles, SEM and TEM images were also obtained for nickel nanoparticles as seen in Figure 3. The operating conditions were maintained similar to those of the experiments performed using ruthenium chloride. The nature of the metal salt had the least impact on the distribution and average particle size. Ruthenium and nickel chloride salts provided similar results 


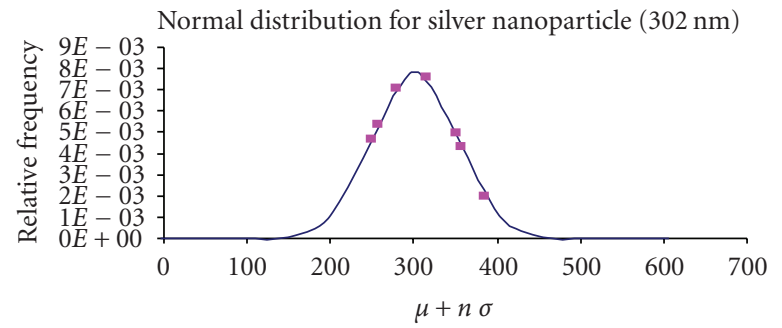

(a)

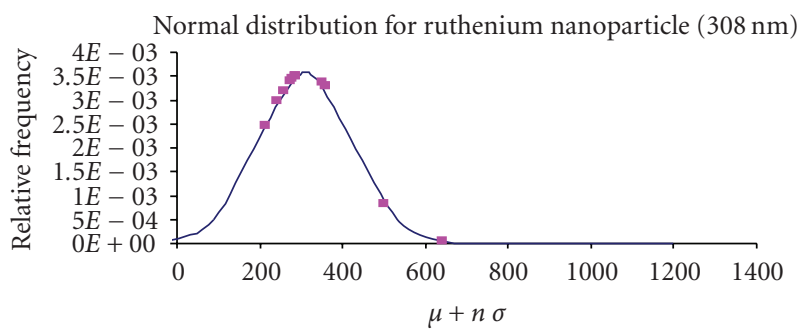

(b)

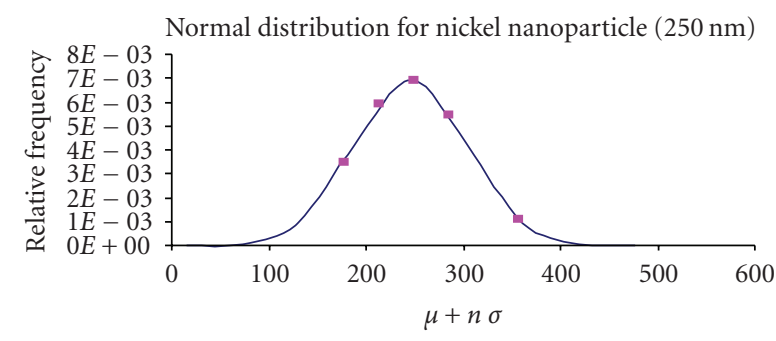

(c)

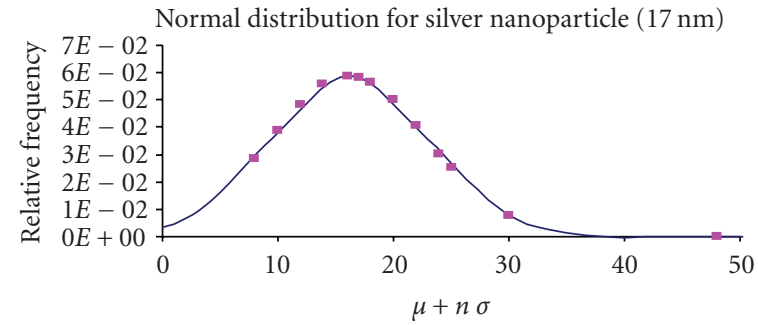

(d)

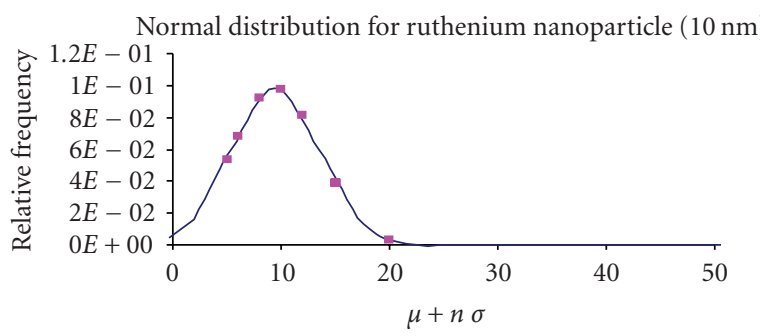

(e)

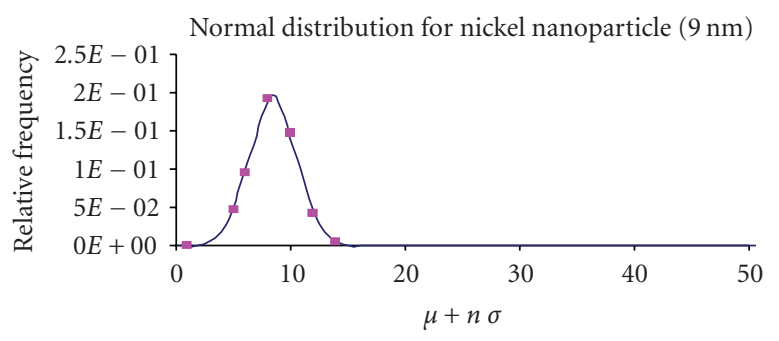

(f)

FIGURE 4: Particle size distribution (PSD) of nanoparticles created in this study. Images (a), (b) and (c) present the PSDs of silver, ruthenium and nickel nanoparticles, respectively, in the absence of ammonium nitrate; while (d), (e) and (f) are PSDs of silver, ruthenium and nickel nanoparticles in the presence of ammonium nitrate, respectively.

TABLE 1: Comparison of average silver particle size with and without ammonium nitrate.

\begin{tabular}{ccccc}
\hline & Experimental conditions & & \multicolumn{2}{c}{ Results } \\
& & & Without $\mathrm{NH}_{4} \mathrm{NO}_{3}$ & With $\mathrm{NH}_{4} \mathrm{NO}_{3}$ \\
\hline Concentration $(\mathrm{N})$ & Power $(\mathrm{W})$ & Temperature $\left({ }^{\circ} \mathrm{C}\right)$ & Size $(\mathrm{nm})$ & Size $(\mathrm{nm})$ \\
$10^{-1}$ & 8 & 800 & 294 & 14 \\
$10^{-1}$ & 8 & 700 & 301 & 17 \\
$10^{-1}$ & 4 & 800 & 310 & 19 \\
\hline
\end{tabular}

TABLE 2: Experimental results for ruthenium nanoparticles synthesized from ruthenium chloride using ammonium nitrate.

\begin{tabular}{ccccc}
\hline & \multicolumn{2}{c}{ Experimental conditions } & & \multicolumn{2}{c}{ Results } \\
& & & Without $\mathrm{NH}_{4} \mathrm{NO}_{3}$ & With $\mathrm{NH}_{4} \mathrm{NO}_{3}$ \\
\hline Concentration $(\mathrm{N})$ & Power $(\mathrm{W})$ & Temperature $\left({ }^{\circ} \mathrm{C}\right)$ & Size $(\mathrm{nm})$ & Size $(\mathrm{nm})$ \\
$10^{-2}$ & 5 & 700 & 350 & 31 \\
$10^{-4}$ & 5 & 700 & 310 & 10 \\
\hline
\end{tabular}

TABLE 3: Experimental results for nickel nanoparticles synthesized from nickel chloride using ammonium nitrate.

\begin{tabular}{ccccc}
\hline & \multirow{2}{*}{ Experimental conditions } & & \multicolumn{2}{c}{ Results } \\
& & & Without $\mathrm{NH}_{4} \mathrm{NO}_{3}$ & $\mathrm{With} \mathrm{NH}_{4} \mathrm{NO}_{3}$ \\
\hline Concentration $(\mathrm{N})$ & Power $(\mathrm{W})$ & Temperature $\left({ }^{\circ} \mathrm{C}\right)$ & Size $(\mathrm{nm})$ & Size $(\mathrm{nm})$ \\
$10^{-2}$ & 5 & 700 & 290 & 24 \\
$10^{-4}$ & 5 & 700 & 246 & 9 \\
\hline
\end{tabular}


as seen from the similar average particle size distributions. Another significant finding in this work was that the average nanoparticle size decreased as the precursor concentration decreased. The effect of concentration of feed solution was seen both with and without the presence of ammonium nitrate. It is evident from Table 2 that the particle decreased from $350 \mathrm{~nm}$ to $310 \mathrm{~nm}$ (without ammonium nitrate) and from $31 \mathrm{~nm}$ to $10 \mathrm{~nm}$ (with ammonium nitrate) for ruthenium nanoparticles when the precursor concentration was decreased from $10^{-2} \mathrm{M}$ to $10^{-4} \mathrm{M}$. Table 3 shows a similar trend for nickel nanoparticles. A detailed discussion of the effect of precursor concentration on the particle size was discussed in our previous work [1]. Operating parameters and the effect of ammonium nitrate in the feedstock were the dominant factors determining size distribution. The particle size distributions for silver, ruthenium, and nickel particles obtained with and without ammonia nitrate are shown in Figure 4. As shown in this figure, the addition of ammonia nitrate to the feed solutions not only reduced the average particle diameter, but also made the nanoparticles more uniformly dispersed.

\section{CONCLUSIONS}

It has demonstrated in experiments the feasibility of adding ammonium nitrate to the precursor solution as a foaming agent to reduce the size of nanoparticles synthesized in the spray-pyrolysis process. The average diameter of silver, ruthenium, and nickel nanoparticles synthesized in spraypyrolysis was reduced from $200-300 \mathrm{~nm}$ to $10-20 \mathrm{~nm}$ after adding ammonium nitrate to the spraying feed solution. It is believed that the ammonia gas generated from the decomposition of ammonium nitrate has significantly reduced the aerosol droplet size and the final size of the metallic nanoparticles.

\section{REFERENCES}

[1] K. C. Pingali, D. A. Rockstraw, and S. Deng, "Silver nanoparticles from ultrasonic spray pyrolysis of aqueous silver nitrate," Aerosol Science and Technology, vol. 39, no. 10, pp. 1010-1014, 2005.

[2] Y.-S. Shon and E. Cutler, "Aqueous synthesis of alkanethiolateprotected Ag nanoparticles using bunte salts," Langmuir, vol. 20, no. 16, pp. 6626-6630, 2004.

[3] F. J. Arriagada and K. Osseo-Asare, "Synthesis of nanosize silica in a nonionic water-in-oil microemulsion: effects of the water/surfactant molar ratio and ammonia concentration," Journal of Colloid and Interface Science, vol. 211, no. 2, pp. 210 220, 1999.

[4] K. Kim, "Plasma synthesis and characterization of nanocrystalline aluminum nitride particles by aluminum plasma jet discharge," Journal of Crystal Growth, vol. 283, no. 3-4, pp. 540546, 2005.

[5] A. Borgna, R. Fréty, M. Primet, and M. Guénim, "Modifications of surface properties of nickel/silica catalysts by nitrogencontaining compounds part I: ammonia," Applied Catalysis, vol. 76, no. 2, pp. 233-254, 1991.

[6] S. Yokoyama, A. Momota, K. Hirao, M. Kawakami, and Y. Murata, "Preparation of fine particles of tin-M (M: silver, bismuth) alloys with ammonia splashing method," Journal of
Materials Processing Technology, vol. 137, no. 1-3, pp. 123-127, 2003.

[7] I. M. Thomas, "Aerial oxidation of tetraethyl silicate and effect on ammonia catalyzed hydrolysis," Journal of Sol-Gel Science and Technology, vol. 13, no. 1-3, pp. 713-716, 1998.

[8] S. K. Park, K. Do Kim, and H. T. Kim, "Preparation of silica nanoparticles: determination of the optimal synthesis conditions for small and uniform particles," Colloids and Surfaces A, vol. 197, no. 1-3, pp. 7-17, 2002.

[9] S. Ivanova, V. Pitchon, Y. Zimmermann, and C. Petit, "Preparation of alumina supported gold catalysts: influence of washing procedures, mechanism of particles size growth," Applied Catalysis A: General, vol. 298, no. 1-2, pp. 57-64, 2006. 

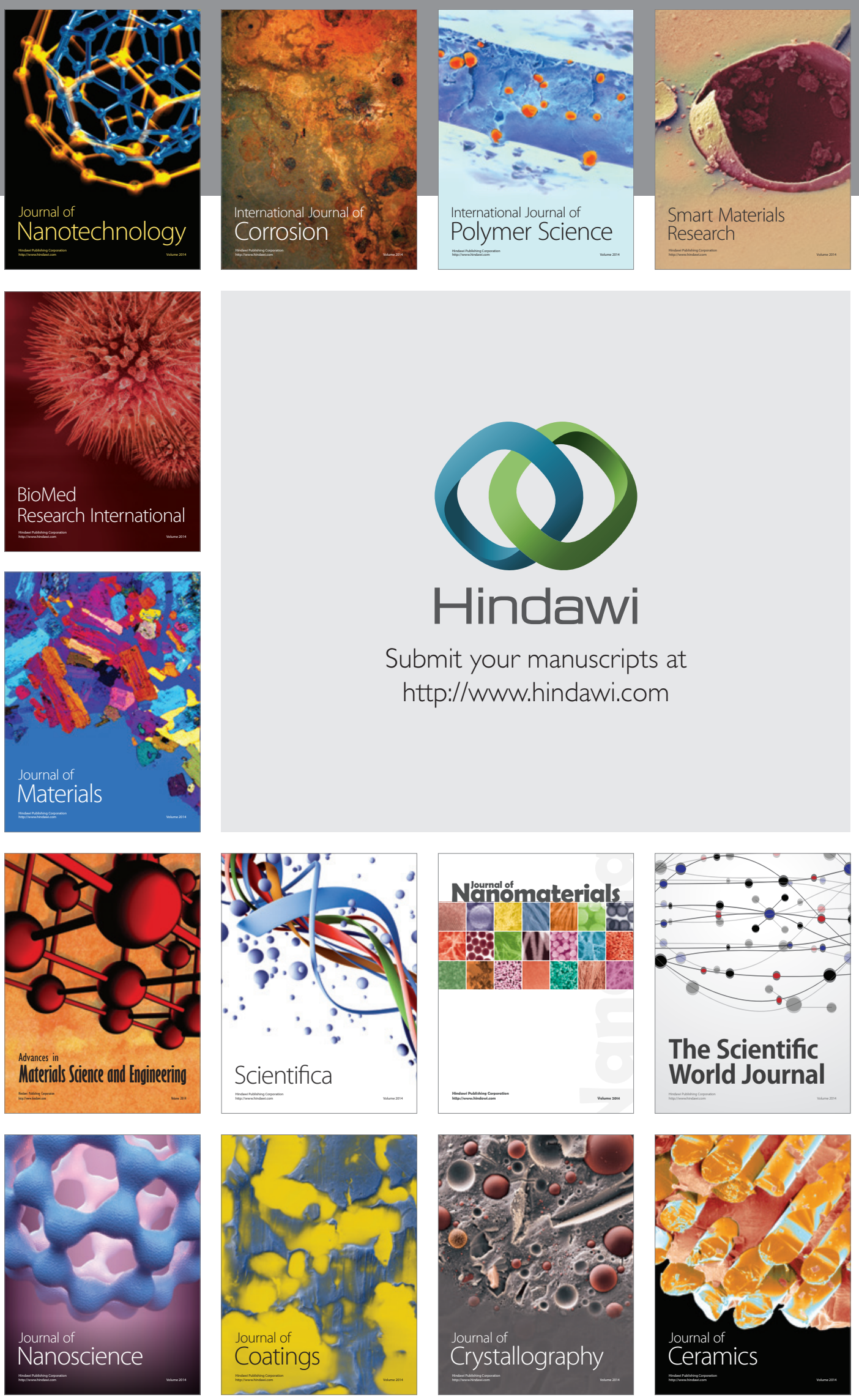

The Scientific World Journal

Submit your manuscripts at

http://www.hindawi.com

\section{World Journal}

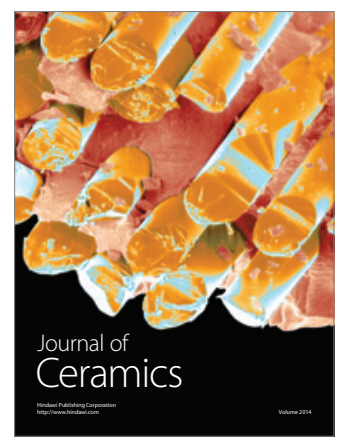

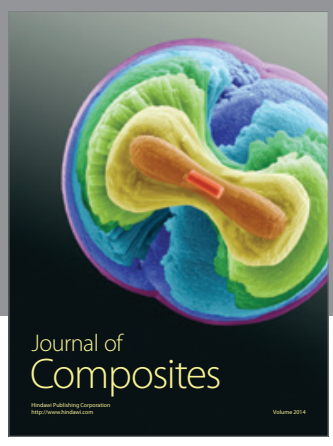
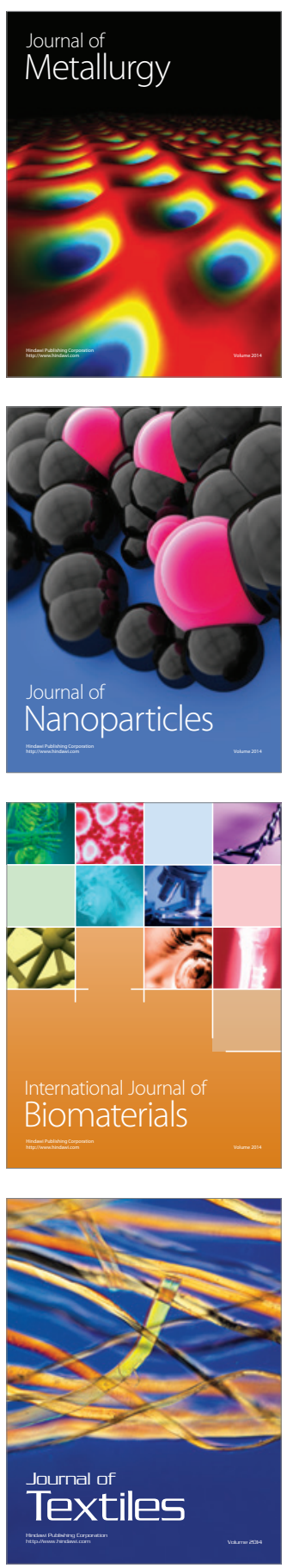